\title{
Prevention of sudden cardiac death in patients with chronic kidney disease
}

\author{
Beata Franczyk-Skóra ${ }^{1}$, Anna Gluba ${ }^{1}$, Maciej Banach²* $^{*}$, Dariusz Kozłowski ${ }^{3}$, Jolanta Małyszko ${ }^{4}$ and Jacek Rysz ${ }^{1}$
}

\begin{abstract}
Cardiovascular deaths account for about $40 \%$ of all deaths of patients with chronic kidney disease (CKD), particularly those on dialysis, while sudden cardiac death (SCD) might be responsible for as many as 60\% of SCD in patients undergoing dialysis. Studies have demonstrated a number of factors occurring in hemodialysis (HD) that could lead to cardiac arrhythmias. Patients with CKD undergoing HD are at high risk of ventricular arrhythmia and SCD since changes associated with renal failure and hemodialysis-related disorders overlap. Antiarrhythmic therapy is much more difficult in patients with CKD, but the general principles are similar to those in patients with normal renal function - at first, the cause of arrhythmias should be found and eliminated. Also the choice of therapy is narrowed due to the altered pharmacokinetics of many drugs resulting from renal failure, neurotoxicity of certain drugs and their complex interactions. Cardiac pacing in elderly patients is a common method of treatment. Assessment of patients' prognosis is important when deciding whether to implant complex devices. There are reports concerning greater risk of surgical complications, which depends also on the extent of the surgical site. The decision concerning implantation of a pacing system in patients with CKD should be made on the basis of individual assessment of the patient.
\end{abstract}

Keywords: Arrhythmias, Chronic kidney disease, Renal failure, Sudden cardiac death

\section{Introduction}

Cardiovascular diseases (CVD) are the cause of about $50 \%$ of deaths in Europe [1,2]. Mortality of patients with chronic kidney disease (CKD) is associated with ischemic heart disease, myocardial infarction (MI) and sudden cardiac death (SCD) [3,4]. CKD is an independent risk factor for coronary artery disease [5]. Nowadays, a growing number of people require renal replacement therapy. In 2003, in Poland, 296 people per million were on renal replacement therapy and 135 people/million had functioning renal grafts [6]. Today the main causes of CKD are the following: diabetic nephropathy, chronic glomerulonephritis and hypertensive nephropathy $[4,5]$.

In CKD patients common factors associated with accelerated atherosclerosis such as hyperlipidemia, hypertension, diabetes, acid-base balance and calcium phosphate metabolism, anemia, high prevalence of vasoconstrictive (angiotensin II) and blood clotting factors,

\footnotetext{
* Correspondence: maciejbanach@aol.co.uk

${ }^{2}$ Department of Hypertension, WAM University Hospital in Lodz, Medical

University of Lodz, Zeromskiego 113, Lodz 90-549, Poland

Full list of author information is available at the end of the article
}

hyperhomocysteinemia and inflammatory factors are frequently present [7-9]. Cigarette smoking, male gender, family history and lack of physical activity are also risk factors for CVD in CKD $[10,11]$. The greater the renal dysfunction, the greater the cardiovascular $(\mathrm{CV})$ risk [11]. Even mild CKD was associated with higher mortality, more frequent hospitalization and the necessity of revascularization after primary coronary artery bypass graft (CABG) surgery during 7-year follow-up [12]. The study by Elsayedi et al. [13] revealed that individuals with CVD and abnormal renal function at baseline are at the greatest risk of rapid progression towards renal failure. Friedman et al. [14] suggested that common risk factors in chronic coronary artery disease (CAD) and CKD as well as atherosclerosis in the renal microcirculation have the greatest impact on the aforementioned phenomena. These studies underline the need for the detection and treatment of CKD in its early stages.

Cardiac arrhythmias are commonly associated with both heart disease and non-cardiovascular diseases, e.g. CKD [15]. In most patients cardiac arrhythmias are not life-threatening, but in the form of malignant ventricular

\section{Biomed Central}

(c) 2012 Franczyk-Skora et al.; licensee BioMed Central Ltd. This is an Open Access article distributed under the terms of the Creative Commons Attribution License (http://creativecommons.org/licenses/by/2.0), which permits unrestricted use, distribution, and reproduction in any medium, provided the original work is properly cited. 
arrhythmia it can lead to sudden cardiac death (SCD) [15]. In recent years, the opinions concerning risk assessment and the treatment of patients with dangerous ventricular arrhythmias have changed. The most significant change refers to the withdrawal of antiarrhythmic drug therapy, which itself may increase the risk of SCD [15]. Currently, the greatest attention is paid to the removal of the cause of arrhythmia and the use of non-pharmacological treatments, such as electrical ablation and the implantation of an automatic cardioverter defibrillator (implantable cardioverter defibrillator, ICD) $[15,16]$.

The current review aims to present the current knowledge on pathogenesis and prevention of SCD in patients with CKD.

\section{Search strategy}

We performed a search of the electronic databases [MEDLINE (1966 - June 2012), EMBASE and SCOPUS (1965 - June 2012), DARE (1966 - 2012)]. Additionally, abstracts from national and international cardiovascular meetings were studied. Where necessary, the relevant authors of these studies were contacted to obtain further data. The main data search terms were: arrhythmias, chronic kidney disease, dialysis, hemodialysis, prevention, renal failure, renal replacement therapy, sudden cardiac death, sudden death, therapy, treatment.

\section{Review}

\section{Cardiac arrhythmias and SCD in patients with CKD}

Cardiovascular deaths account for about $40 \%$ of all deaths of patients with chronic renal failure, particularly those on dialysis [17]. Hypertension which leads to the occurrence of left ventricular hypertrophy (LVH), heart failure (HF) and CAD or coexists with them plays the main role in the development of serious ventricular arrhythmias $[18,19]$. LVH essentially increases the risk of sudden cardiac death [20]. Half of patients with significant LVH develop symptoms of HF [13,14]. In the group of patients with end-stage renal disease (ESRD) and with hypertrophy (left ventricular mass index [LVMI] $>125 \mathrm{~g} / \mathrm{m}^{2}$ ) 5-year survival was $20 \%$, and $50 \%$ when the LVMI was $<125 \mathrm{~g} / \mathrm{m}^{2}[13,14]$. This is mainly due to QT prolongation and the increase in its dispersion. QT prolongation is typical for dialysis patients $[13,14]$. According to Herzog's study [21] SCD might be responsible for as many as $60 \%$ of deaths in patients undergoing dialysis. Another study of 4,120 deaths during the 2-year follow-up of 12,833 hemodialysis patients revealed that the greatest percentage of all deaths (27\%) was caused by sudden cardiac arrest, while other CV conditions accounted for $20 \%$ of all deaths [15,22]. In the another study by Herzog et al. [23], deaths from sudden cardiac arrest or arrhythmia accounted for approximately $25 \%$ of all-cause deaths. The study by Pun et al. [24] demonstrated an increased rate of SCD with increasing severity of CKD. Each $10 \mathrm{ml} / \mathrm{min} / 1.73 \mathrm{~m}^{2}$ decline in eGFR was associated with increased risk of SCD (hazard ratio $[\mathrm{HR}]=1.11$; 95\% CI 1.06-1.17, $p<0.001$ ) [24].

According to studies the frequency of SCD increases with the time of dialysis treatment and with the time that passed from their previous dialysis session and it is highest among individuals with diabetes [25-27]. It was observed that the frequency of deaths of HD patients was higher than the expected ratio in the $12 \mathrm{~h}$ period from the beginning of dialysis treatment and on the last day of the dialysis-free weekend interval. The rate of cardiac arrest among patients with diabetes who were undergoing dialysis was 110 events per 1,000 patientyears at year one and rose to 208 events per 1,000 patient-years at year four $[23,25]$. In the already mentioned study by Herzog et al. [12] the survival rates after cardiac arrest were $32 \%$ at 30 days and $17 \%$ at 1 year after dialysis and dropped to $13 \%$ at 1 year in patients with diabetes.

Among other risk factors for SCD it is worth mentioning the hospitalization within 30 days after dialysis and a decrease of $30 \mathrm{~mm} \mathrm{Hg}$ in systolic blood pressure (SBP) during hemodialysis [27]. Moreover, patients with ESRD and diabetes are at higher risk of sudden death than non-diabetic ESRD patients [28].

Previous studies have noted a number of factors occurring with HD that could lead to cardiac arrhythmias [15]. Patients with CKD undergoing hemodialysis are at high risk of ventricular arrhythmia and SCD since changes associated with renal failure and hemodialysisrelated disorders overlap. It was revealed that ventricular arrhythmia is present in $90 \%$ and supraventricular arrhythmia in $80 \%$ of dialysis patients [15]. Cardiac arrhythmias are exacerbated by dialysis and several hours after it [15]. During dialysis, many changes occur that favor electrical instability, including disturbances in serum electrolytes, variations in various metabolite concentrations, acid-base balance alterations, the decrease in circulating blood volume, sympathetic overactivity as well as inflammation and possibly iron deposition $[15,21,26]$. Too low concentration of potassium in the dialysate, diabetes mellitus, advanced age and dialysis performed after the weekend break are important factors that increase the risk of SCD $[26,29]$. The study by Karnik et al. [26] showed that patients who died in the first $12 \mathrm{~h}$ interval had a lower mean serum potassium level in the prior monthly tests than those dying in the 60-72 $\mathrm{h}$ interval. Moreover, iron overload in ESRD increases the risk of SCD due to QT prolongation [29].

Concentric hypertrophy leads to the reduced susceptibility of the left ventricle $[14,19]$. In this situation, the 
ventricular filling pressure increases so that the ventricle could be filled sufficiently to ensure adequate cardiac output. The rise in filling pressure results in the appearance of symptoms of pulmonary congestion. On the other hand, the greater sensitivity of the hypertrophic ventricle results in its higher susceptibility to the occurrence of dialysis hypotension [30]. All these conditions favor the occurrence of serious ventricular arrhythmias and SCD. LVH increasing the risk of sudden death is associated with prolongation of the corrected QT interval or with increasing arrhythmogenesis [29].

According to studies also prolonged QT interval, QTc, and torsade de pointes occurring in CKD and ESRD can be a cause of sudden cardiac death [31]. Prolonged QTc in these patients results from inhomogeneity of myocardial depolarization and repolarization following $\mathrm{LVH}$ as well as intercardiomyocytic fibrosis [31,32]. Moreover, in patients with greater increases in QTc intervals after hemodialysis, baseline plasma calcium levels are higher and lower after hemodialysis, which suggests that QTc prolongation may be a result of calcium hemostasis abnormalities and may induce or predispose to sudden death [33]. A retrospective cohort study conducted on patients on dialysis QTc interval dispersion which occurred for longer than $74 \mathrm{~ms}$ was an independent predictor of all-cause mortality, CV mortality and arrhythmia-related mortality [34].

In patients with CKD inflammation can be also a common trigger of sudden cardiac death as a result of either premature atherosclerosis, and cytokine-induced plaque instability or by a direct effect on the myocardium and the electrical conduction system [35-37]. In this group of patients the level of toxins, proinflammatory cytokines, inflammatory mediators and reactive oxygen species (ROS) increases as renal function deteriorates [36-39]. Elevated levels of inflammatory mediators, the accumulation of asymmetric dimethylarginine, high levels of homocysteine as well as raised levels of calcification promoters (e.g. osteopontin), diminished levels of calcification inhibitors (e.g. fetuin-a) and abnormal calcium-phosphate metabolism are associated with atherosclerosis, atherothrombotic events and incident $\mathrm{CV}$ mortality in patients with CKD and those undergoing hemodialysis [40-43].

Myocardial ischemia is the most common cause of malignant ventricular arrhythmias in patients with CKD. CAD probably causes arrhythmogenesis in patients on hemodialysis since severe coronary stenosis is associated with the induction and lengthy persistence of ventricular arrhythmias during and after hemodialysis $[15,44,45]$. Arrhythmia also results from fibrosis and cardiac hypertrophy. Additional contractions and other changes in heart rate are its direct triggers. Ischemia, fluid and electrolyte disorders, autonomic neuropathy, anemia, ion disorders caused by the use of diuretics and valvular calcification are the modifying factors, which sometimes also become the triggering ones $[15,21,26,46,47]$.

Ischemia is probably the most common factor which modifies the risk or elicits arrhythmia, but the role of changes in calcium-phosphate metabolism resulting in heart valve calcification should also be emphasized. These changes affect the efficiency of the heart and promote the occurrence of arrhythmias [48,49].

\section{The identification of patients at risk of SCD}

The stratification of SCD risk in patients with CKD/ renal failure has been poorly studied so far. Many studies have shown that elevated levels of troponin $\mathrm{T}(\mathrm{TnT})$, creatine kinase-MB (CK-MB) fraction or C-reactive protein (CRP) are associated with increased risk of death from CV causes. However, it is not known whether these markers also indicate the risk of sudden cardiac death [4]. The following risk factors for SCD in patients on dialysis are the most commonly mentioned: (1) demographic factors: male gender, black race, (2) data from family history: positive family history, smoking, low physical activity, (3) cardiovascular disease: hypertension, left ventricular hypertrophy (LVH), myocardial infarction (MI), angina pectoris, and (4) other diseases, such as: diabetes, hyperlipidemia, anemia, hyperparathyroidism, metabolic acidosis $[4,24,35]$.

Patients at high risk of SCD can be also identified on the basis of markers of coronary ischemia such as ischemia modified albumin (IMA) or cardiac troponin [50]. Ischemia modified troponin is a novel biomarker which predicted all-cause mortality in ESRD patients with a sensitivity and specificity of $76 \%$ and $74 \%$, respectively [50]. Elevated cardiac troponin $(\geq 0.06 \mu \mathrm{g} / \mathrm{l})$ predicted mortality with a sensitivity of $75 \%$ and a specificity of $72 \%$ [50]. Cardiac mortality risk was 7-fold higher in patients with elevated levels of both IMA and cardiac troponin (OR 7.12, 95\%CI 4.14-10.12, $p=0.005$ ) [50]. According to studies also severely impaired myocardial fatty acid metabolism due to recurrent myocardial ischemia may indicate those patients on dialysis who are at high risk of SCD [51].

Other small studies have shown that heart rate variability analysis and the assessment of baroreceptor sensitivity may also have predictive value. Impaired baroreflex effectiveness and sensitivity and obstructive sleep apnea may increase the risk of sudden death [52]. In the study of Johansson et al. [52] baroreflex sensitivity was reduced by $51 \%$ and the baroreflex effectiveness index by $49 \%$ in patients with hypertension and stage 4 or 5 CKD in comparison to age-matched healthy controls. According to another Johansson et al. [53] study, reduced baroreflex sensitivity was an independent predictor of SCD. The results of the German Diabetes 
Dialysis Study (4D) study demonstrated that $40 \%$ of people who died as a result of sudden cardiac arrest were found dead in bed in the morning, which according to the investigators might have been related to obstructive sleep apnea [54]. However, there were no measures or objective data available to support this conclusion. Moreover, this study revealed that low baseline homoarginine concentration was a strong risk factor for SCD and HF death during 4-year follow-up [55]. Another analysis of 4D data showed that poor glycemic control and vitamin $\mathrm{D}$ deficiency were also strongly associated with the incidence of SCD in dialysis patients [56]. Despite the progress of technology and numerous studies, current knowledge concerning the evaluation of risk SCD factors is still too limited to sufficiently explain the excess rate of such deaths in dialysis patients [55].

\section{Antiarrhythmic management in CKD patients}

Antiarrhythmic therapy is much more difficult in patients with CKD, but the general principles are similar to those in patients with normal renal function. First of all, the cause of arrhythmias should be found and eliminated. In patients with CKD it is mainly based on very rigorous control of water and electrolyte balance. Antiarrhythmic drugs can be used in this group of patients but with limited effectiveness. The choice of therapy is limited due to the altered pharmacokinetics of many drugs resulting from renal failure, neurotoxicity of certain drugs and their complex interactions [57]. Beta-blockers should be the drugs of choice because of their lower risk of proarrhythmia [58,59]. The Multicenter Automatic Defibrillator Implantation Trial-II (MADIT II) study demonstrated that the use of these drugs was associated with a significant reduction in SCD risk in patients with CKD [60]. In another randomized controlled trial, carvedilol therapy reduced morbidity, all-cause and cardiovascular mortality (by 29.3\%) in dialysis patients with ESRD and dilated cardiomyopathy [61]. The large $(43,200$ hemodialysis patients) retrospective study by Pun et al. revealed that beta-blockers were more frequently prescribed to patients who survived than to those who died from SCD (53\% vs 40\%, or 0.59 , 95\% CI $0.43-0.80$, $p=0.0007$ ) [62]. Moreover, according to this study betablockers were associated with a significantly lower risk of death at $24 \mathrm{~h}$ and 6 months after cardiac arrest [62].

Amiodarone seems to be the most effective antiarrhythmic drug used in the treatment of ventricular arrhythmia and atrial fibrillation. However, its numerous non-cardiac actions should be kept in mind [63]. In dialysis patients the reduction of SCD risk was achieved through the introduction of bicarbonate dialysis, modification of dialysis fluid composition (potassium and calcium concentration) depending on the clinical situation, rapid restoration of water-electrolyte and acid-base balance as well as monitoring of heart rhythm [64]. However, it is common knowledge that the implantation of automatic cardioverter-defibrillators (ICD) both as a primary and secondary prevention is the only effective way of preventing SCD [57]. Though ICD implantation decreases the risk of SCD, there are hardly any trials concerning the use of ICD in patients with advanced renal insufficiency [14]. The ICD is a device that works symptomatically and thus it does not decrease the risk of arrhythmic events, in contrast to coronary revascularization, optimal pharmacotherapy or cardiac resynchronization in HF $[65,66]$. Published data (MADIT II study) show that ICD implantation contributed to reduction in total mortality in primary and secondary prevention, and reduction in mortality from arrhythmia causes in a population of patients after myocardial infarction [67]. On the basis of the results of the aforementioned studies, guidelines considering the indications for ICD implantation were defined [68]. According to them, an ICD should be implanted as the secondary prevention in patients who survived cardiac arrest in the course of malignant ventricular arrhythmias unless arrhythmia occurred within the first 24-48 h after fresh myocardial infarction (class I of recommendation, level A of evidence). During the first 24-48 h ventricular arrhythmia is a symptom of acute ischemia, and treatment should refer to immediate and optimal coronary revascularization [68]. In the primary prevention of SCD, ICD should be implanted within 40 days after $\mathrm{MI}$ in patients with the EF $30-40 \%$, in NYHA class II-III, receiving optimal pharmacological treatment and with predicted survival in good functional condition for at least one year (class I of recommendation, level A of evidence) [68].

The analysis of these recommendations reveals the existence of the so-called 'grey area' between $48 \mathrm{~h}$ and 40 days after MI. This early post-myocardial period raises the most controversy concerning SCD risk stratification and the possible implantation of ICD in primary prevention of SCD [69]. It is known that the risk of SCD is highest in that period. In the Valsartan in Acute Myocardial Infarction Trial (VALIANT) [70], 19\% of patients died suddenly or were resuscitated within 30 days after myocardial infarction and 70\% of all SCD occurred during the first year after MI. Although ICD implantation reduced the number of arrhythmic deaths, patients with implanted ICD died more often due to non-arrhythmic causes (non-SCD) [68-70].

On the basis of the aforementioned studies it can be concluded that while the ICD effectively interrupts ventricular arrhythmias in a population of patients who would suddenly die from arrhythmic causes without this device, it also contributes to the increased number of non-arrhythmic deaths. It was hypothesized that high energy therapies might have an adverse impact on the 
occurrence or exacerbation of HF in patients after MI $[68,71]$. The MADIT II study demonstrated that adequate ICD cardioversion/defibrillation increases threefold and inadequate defibrillation increases twofold the overall mortality [67]. This indicates high importance of correct and optimal programming of implanted devices in order to minimize the frequency of inappropriate ICD therapy. It is also known that the benefits of the implanted ICD increase with time after MI. The MADIT II study revealed a reduction in mortality and the greatest benefit from ICD implantation after over 18 months after myocardial infarction $[67,69]$.

The study by Dasgupta et al. [72] conducted on 41 patients with ESRD and 123 controls demonstrated high complication rates for cardiac rhythm management devices (permanent pacemakers or implantable cardioverter-defibrillators) in this group of patients. Pneumothorax requiring a chest tube, pocket infection requiring device extraction, or thrombosis occurred in $29 \%$ of ESRD patients versus $5 \%$ of controls $(p<0.001)$ while minor complications occurred in $17 \%$ of ESRD patients versus $6 \%$ of controls $(p<0.03)$. However, no fatal complications were seen in either group [72]. A retrospective study of patients with ICD implanted due to primary or secondary indications revealed that renal insufficiency was a strong predictor of appropriate ICD shocks [73]. One-year incidence of appropriate ICD shock was 37.5\% for patients on dialysis and $10.7 \%$ for those not on dialysis $(p<0.0001)$ [73].

The study of patients with or without CKD who received an ICD for primary prevention of sudden cardiac death demonstrated that 1-year survival of patients with CKD was lower (61.2\%) than that of patients without CKD $(96.3 \%)(p<0.00001)$ [74]. In this study CKD was the most significant independent predictor of mortality (HR 10.5, 95\%CI 4.8-23.1, $p<0.00001$ ) [74]. The study of Korantzopoulos et al. [75], which demonstrated increased mortality in patients who receive ICD therapy, suggested that patients with advanced renal insufficiency could be less responsive to ICD therapy, probably due to higher defibrillation thresholds. Until the reasons for that phenomenon are explained it seems rational that patients with CKD and implanted ICD should be more frequently tested using the technique of programmed ventricular stimulation than patients with normal renal function [75]. This will help to determine the threshold of effective defibrillation. It is also possible that the incidence of infectious complications related to ICD implantation may be greater in this group. These and other factors are responsible for the lower frequency of ICD implantation in dialysis patients who survived cardiac arrest [75].

However, according to Herzog et al. [76] ICD implantation in cardiac arrest survivors on dialysis is associated with greater survival. They observed that estimated 1-, 2-, 3-, 4-, and 5-year survival after day 30 of admission in the ICD group were higher $(71 \%, 53 \%, 36 \%, 25 \%$, and $22 \%$, respectively) in comparison to the no-ICD group $(49 \%, 33 \%, 23 \%, 16 \%$, and $12 \%)(p<0.0001)$. In this study ICD implantation was associated with a $42 \%$ reduction in death risk [76].

It should be kept in mind that not all arrhythmic events are interrupted by the ICD, as it is in the case of e.g. pulseless electrical activity after ICD testing, permanent ventricular tachycardia or acute HF after defibrillation. Moreover, not every SCD results from arrhythmic causes or even CV-related ones. SCD (defined as sudden death occurring within one hour of the beginning of clinical symptoms) may well be the result of pulmonary embolism, aortic aneurysm dissection, stroke, etc. $[68,77]$. According to publications, worse survival and higher incidence of SCD were observed in patients with both ICD and CKD compared to patients with normal renal function [68,77-80].

According to the study by Cuculic et al. $[14,74]$ in patients receiving an ICD for primary prevention of SCD, CKD significantly reduced long-term survival, which may limit the benefits of ICD therapy in this population. When making the decision concerning implantation of a ICD for primary prevention of sudden cardiac death in patients with CKD, the patient's age and the stage of kidney disease should be taken into account [78]. According to this study ICDs reduce mortality in patients with stage 1 and 2 CKD. The benefits of ICD implantation are less notable in patients with stage 3-5 CKD [78]. These results could be explained by a higher procedural risk and complications in addition to decreased life expectancy in patients with advanced CKD $[14,78]$. Moreover, benefits of ICD implantation are age-dependent. Cardioverter-defibrillator implantation seems to be preferential in patients aged $<80$ years with GFR $30-59 \mathrm{ml} / \mathrm{min} / 1.73 \mathrm{~m}^{2}$, aged $<75$ years with GFR $15-29 \mathrm{ml} / \mathrm{min} / 1.73 \mathrm{~m}^{2}$ and aged $<65$ years with GFR $<15 \mathrm{ml} / \mathrm{min} / 1.73 \mathrm{~m}^{2}$ [78].

A prospective study of the effectiveness of automatic cardioverter-defibrillators in a population of CKD patients is particularly necessary due to the very high incidence of sudden death in these patients. The role of drugs/invasive therapies in the prevention and treatment of SCD in CKD patients are briefly summarized in Table 1.

\section{The role of electrostimulation}

Pathological bradyarrhythmias $(<50 / \mathrm{min})$ resulting from sinus node or AV conduction dysfunction are responsible for $15-20 \%$ of SCDs $[67,68]$. Therefore, the implantation of classic one- and two-electrode stimulators, as well as pacemaker systems, is extremely important in 
Table 1 The role of drugs/invasive therapies in the prevention and treatment of SCD in CKD patients

\begin{tabular}{|c|c|c|c|c|c|c|}
\hline $\begin{array}{l}\text { DRUG/ } \\
\text { DEVICE }\end{array}$ & POPULATION & $\begin{array}{l}\text { TYPE OF } \\
\text { STUDY }\end{array}$ & $\begin{array}{l}\text { NO. OF } \\
\text { PTS. }\end{array}$ & RESULTS & $\begin{array}{l}\text { LEVEL OF } \\
\text { SIGNIFICANCE }\end{array}$ & REF. \\
\hline $\begin{array}{l}\text { BETA- } \\
\text { BLOCKERS }\end{array}$ & $\begin{array}{l}\text { CKD (eGFR of }<75 \mathrm{ml} / \\
\left.\text { min/1.73 } \mathrm{m}^{2}\right) \text { with LV } \\
\text { dysfunction }\end{array}$ & $\begin{array}{l}\text { Post-hoc } \\
\text { analysis }\end{array}$ & 1232 & $\begin{array}{l}\text { MADIT II study. Reduced risk of arrhythmic mortality } \\
\text { in HF patients with mild renal insufficiency. }\end{array}$ & $\begin{array}{l}\text { HR } 0.61 .95 \% \\
\mathrm{Cl} ; 0.38-0.99\end{array}$ & $\overline{[60]}$ \\
\hline $\begin{array}{l}\text { BETA- } \\
\text { BLOCKERS }\end{array}$ & $\begin{array}{l}\text { HD patients who } \\
\text { underwent cardiac } \\
\text { arrest }\end{array}$ & $\begin{array}{l}\text { Nested case- } \\
\text { control cohort } \\
\text { study }\end{array}$ & 729 & $\begin{array}{l}\text { Significantly reduced risk of death with beta- } \\
\text { blockers* at } 24 \mathrm{~h}^{* *} \text { at the } 6 \text {-month time points } \\
\text { Strongly predictive for survival. }\end{array}$ & $\begin{array}{l}* \text { OR } 0.32 ; 95 \% \\
\text { Cl } 0.17-0.61 \\
{ }^{* *} p=0.005 \\
{ }^{* * *} p<0.001\end{array}$ & {$[62]$} \\
\hline CARVEDILOL & $\begin{array}{l}\text { Dialysis patients with } \\
\text { dilated cardiomyopathy }\end{array}$ & $\begin{array}{l}\text { Prospective, } \\
\text { randomized, } \\
\text { placebo } \\
\text { controlled }\end{array}$ & 114 & $\begin{array}{c}\text { Reduced morbidity* and mortality** in dialysis } \\
\text { patients with dilated cardiomyopathy. Carvedilol use } \\
\text { is recommended in all dialysis patients with chronic } \\
\text { HF. }\end{array}$ & $\begin{array}{l}* p<0.00001 \\
{ }_{* *}^{*} p<0.01\end{array}$ & $\overline{[61]}$ \\
\hline$\overline{I C D}$ & $\begin{array}{l}\text { ESRD patients and } \\
\text { controls who had } \\
\text { permanent pacemaker } \\
\text { or ICD }\end{array}$ & $\begin{array}{l}\text { Observational } \\
\text { study }\end{array}$ & $\begin{array}{l}41 \text { with } \\
\text { ESRD; } 123 \\
\text { controls }\end{array}$ & $\begin{array}{c}\text { Patients with renal insufficiency are more prone to } \\
\text { develop ventricular tachyarrhythmia and receive } \\
\text { appropriate ICD shocks }{ }^{2} \text {. }\end{array}$ & ${ }^{*} p<0.001$ & $\overline{[72]}$ \\
\hline ICD & $\begin{array}{l}\text { Patients with renal } \\
\text { insufficiency and ICD }\end{array}$ & Prospective & 230 & $\begin{array}{l}\text { Renal insufficiency is a strong predictor of ICD } \\
\text { shocks and antitachycardia pacing. }\end{array}$ & $p=0.02$ & {$[73]$} \\
\hline ICD & $\begin{array}{l}\text { CKD patients who } \\
\text { underwent ICD }\end{array}$ & $\begin{array}{l}\text { Retrospective } \\
\text { study }\end{array}$ & $\begin{array}{l}35 \text { with CKD } \\
\text { (total 229) }\end{array}$ & $\begin{array}{l}\text { In patients receiving an ICD for primary prevention } \\
\text { of sudden death, CKD significantly reduced long- } \\
\text { term survival. }\end{array}$ & $\begin{array}{l}\text { HR } 10.5 ; 95 \% \\
\text { Cl } 4.8-23.1 \\
p=0.0001\end{array}$ & {$[74]$} \\
\hline ICD & $\begin{array}{l}\text { CKD with } I C D^{*} \text { or eGFR } \\
<60 \mathrm{~mL} / \mathrm{min} / 1.73 \mathrm{~m}^{2^{* *}} \\
\text { with ICD }\end{array}$ & Meta-analysis & 3010 & $\begin{array}{l}\text { CKD is associated with increased mortality in } \\
\text { patients who receive ICD therapy. }\end{array}$ & $\begin{array}{c}\mathrm{HR}=3.44,95 \% \\
\mathrm{Cl} 2.82-4.21, p \\
<0.001^{*} \\
\mathrm{HR}=3.06,95 \% \\
\mathrm{Cl} 22.31-4.04, \mathrm{p} \\
<0.001^{* *^{\prime}}\end{array}$ & {$[75]$} \\
\hline ICD & $\begin{array}{l}\text { Dialysis patients with } \\
\text { ventricular fibrillation/ } \\
\text { cardiac arrest and ICD }\end{array}$ & $\begin{array}{l}\text { Retrospective } \\
\text { cohort } \\
\text { observational } \\
\text { study }\end{array}$ & $\begin{array}{l}460(\mathrm{ESRD}+ \\
\text { ICD), } 5582 \\
\text { without ICD }\end{array}$ & $\begin{array}{c}\text { Estimated } 1 \text { to } 5 \text {-year survival after ICD implantation } \\
\text { was better than in the non-ICD group*. ICD } \\
\text { implantation was independently associated with a } \\
42 \% \text { reduction in death risk** }\end{array}$ & $\begin{array}{c}{ }^{*} p<0.0001 \\
{ }^{* *} \mathrm{RR} 0.58 \\
95 \% \mathrm{Cl} 0.50- \\
0.66\end{array}$ & {$[76]$} \\
\hline ICD & CKD patients with ICD & $\begin{array}{l}\text { Prospective } \\
\text { study }\end{array}$ & - & $\begin{array}{c}\text { The beneficial effect of an ICD for primary } \\
\text { prevention of SCD in CKD patients depends } \\
\text { primarily on the patient's age and stage of renal } \\
\text { disease. ICD implantation in stages I-II reduces } \\
\text { mortality, but in more advanced stages, advantages } \\
\text { are less pronounced and are age-dependent due to } \\
\text { higher procedural risk and decreased life } \\
\text { expectancy. }\end{array}$ & - & {$[78]$} \\
\hline
\end{tabular}

ABBREVIATIONS: SCD, sudden cardiac death; CKD, chronic kidney disease; MADIT II, Multicenter Automatic Defibrillator Implantation Trial-II; $H R$, hazard risk; OR, odds ratio; $H F$, heart failure; VALIANT, Valsartan in Acute Myocardial Infarction Trial; ICD, implanted cardioverter-defibrillator; ESRD, end-stage renal disease, RR, risk reduction.

the prevention of SCD. Sinus node disease, known as sick sinus syndrome (SSS), involves the entire group of sino-atrial disorders, from sinus bradycardia to sinus inhibition or so-called bradycardia-tachycardia syndrome. Sinus node disease occurs much more frequently in elderly patients and it is believed to be a major reason for permanent pacemaker implantation in this group $[67,68,81,82]$. Sinus node degeneration progresses with age, which means the reduction of the number of nodal cells, and the increase in the content of connective tissue and fat mainly in the nodal area. Symptoms of this disease include decreased exercise tolerance and cognitive impairment (mainly in elderly patients) due to bradycardia and chronotropic insufficiency resulting from the inability to properly increase heart rate in response to exercise. Atrial tachyarrhythmia occurring after a sinus pause may increase the heart rate so strongly that it may lead to hypotension and loss of consciousness. Elderly people lose consciousness easily due to numerous other contributory factors, such as baroreceptor failure, polytherapy and changes in the cerebral vessels $[67,68,81,82]$. The determination of indications for pacemaker implantation in patients with sinus node disease should be preceded by a detailed differential diagnosis including cerebral circulation disorders, which can also be a cause of dizziness, balance impairment or loss of consciousness [82].

The selection of stimulation type in patients with sinus node disease should depend on the type of disorders and symptoms. CKD is not a contraindication for the 
implantation of dual-chamber pacing with the minimization of right ventricular stimulation. Such procedures are validated by the improvement of the quality of life resulting from the limitations of atrial fibrillation attacks, which are in elderly patients a common cause of significant cardiac decompensation. Moreover, in patients with sinus node disease, there is a risk of future atrioventricular conduction disorders $[68,82]$.

\section{Implantation of cardiac resynchronization system}

Cardiac resynchronization therapy (CRT) with or without ICD is used to treat advanced HF accompanied by inter- and intraventricular conduction abnormalities leading to significant desynchronization of chambers $[83,84]$. CRT is complementary to optimal drug therapy. The Comparison of Medical Therapy, Pacing and Defibrillation in Heart Failure (COMPANION) study compared the clinical effects of CRT-D or CRT-P system implantation $[84,85]$. The analysis of the results from this study revealed that only CRT-D system implantation was associated with a significant reduction in the risk of SCD. According to the 2010 guidelines concerning HF and cardiac resynchronization therapy, CRT should be implanted in the following patients: (1) with heart failure (NYHA class III or IV), EF <35\%, QRS $>120$ ms, sinus rhythm, treated with a stable pharmacological medical regimen. Furthermore, patients in NYHA class IV should not be hospitalized for HF during the month prior to device implantation and their expected survival should be longer than 6 months (I/A); (2) with heart failure in NYHA class II, EF <35\%, QRS > $150 \mathrm{~ms}$, sinus rhythm, treated with a stable pharmacological medical regimen (I/A) [86].

The implantation of CRT systems is more and more common due to both the extension of indications as well as greater availability of this method. The effectiveness of resynchronization was not assessed in patients with CKD. However, it seems highly possible that this method can be effective also in patients with CKD and symptoms of systolic HF and contraction asynchronism.

\section{Conclusions}

Over the last decade, numerous studies have confirmed the strong association between CKD and an increased risk of cardiovascular diseases. The decision concerning the implantation of a pacing system in patients with CKD should be made on the basis of careful individual assessment of the patient. Treatment of arrhythmias in patients with CKD is more difficult than in patients with preserved renal function. The control and correction of electrolyte disturbances, the treatment of cardiovascular disease, and the implantation of ICD in patients at highest risk are very important in this group of patients [87-91].

\section{Competing interests}

The authors declare that they have no competing interests.

\section{Authors' contributions}

BFS and AG participated in the design of the study, made the literature search and drafted the manuscript. MB participated in the design of the study and prepared the final version of the manuscript as well as responses to reviewers. DK, JM and JR participated in the coordination and helped to draft the manuscript. All authors read and approved the final manuscript.

\section{Acknowledgements}

There were no sources of funding for both the authors, and for the manuscript preparation.

\section{Author details}

${ }^{1}$ Department of Nephrology, Hypertension and Family Medicine, Medical University of Lodz, Lodz, Poland. 'Department of Hypertension, WAM University Hospital in Lodz, Medical University of Lodz, Zeromskiego 113, Lodz 90-549, Poland. ${ }^{3}$ Department of Cardiology and Electrotherapy, Second Chair of Cardiology, Medical University of Gdansk, Gdansk, Poland. ${ }^{4}$ Department of Nephrology and Transplantology, Medical University, Bialystok, Poland.

Received: 8 July 2012 Accepted: 27 November 2012

Published: 3 December 2012

\section{References}

1. European Cardiovascular Disease Statistics. 2012, http://www.ehnheart. org/cvd-statistics.html.

2. Allender S, Scarborough P, Peto V, Rayner M, Leal J, Luengo-Fernandez R, Alastair G: European cardiovascular disease statistics. http://www. herzstiftung.ch/uploads/media/ European_cardiovascular_disease_statistics_2008.pdf.

3. Athyros VG, Hatzitolios Al, Karagiannis A, et al: IMproving the imPlemEntation of cuRrent guidelines for the mAnagement of major coronary hearT disease rlsk factors by multifactorial interVEntion. The IMPERATIVE renal analysis. Arch Med Sci 2011, 7:984-992.

4. USRDS Annual Data Report. Cardiovascular special studies. http://www. usrds.org/2004/pdf/09_cardio_04.pdf.

5. ERA-EDTA Registry: Annual Report. 2010, http://www.era-edta-reg.org/files/ annualreports/pdf/AnnRep2010.pdf.

6. Puka J, Rutkowski B, Lichodziejewska-Niemierko M, et al: Report on renal replacement therapy in Poland in 2003. Gdańsk: MAK-media; 2004 (in Polish).

7. Gluba A, Mikhailidis DP, Lip GY, Hannam S, Rysz J, Banach M: Metabolic syndrome and renal disease. Int J Cardiol 2012, doi:10.1016/j. ijcard.2012.01.013.

8. Malyszko J, Bachorzewska-Gajewska H, Malyszko J, laina-Levin N, Kobus G, Dobrzycki S: Markers of kidney function in the elderly in relation to the new CKD-EPI formula for estimation of glomerular filtration rate. Arch Med Sci 2011, 7:658-664.

9. Rysz J, Aronow WS, Stolarek RS, Hannam S, Mikhailidis DP, Banach M: Nephroprotective and clinical potential of statins in dialyzed patients. Expert Opin Ther Targets 2009, 13:541-550.

10. Park SH, Stenvinkel P, Lindholm B: Cardiovascular biomarkers in chronic kidney disease. J Ren Nutr 2012, 22(1):120-127.

11. Anavekar NS, MC Murmay JJ, Velazquez EJ, et al: Relation between renal dysfunction and cardiovascular outcomes after myocardial infarction. N Eng J Med 2004, 351:1285-1295.

12. Szczech LA, Best PJ, Crowley E, et al: Outcomes of patients with chronic renal insufficiency in the bypass angioplasty revascularization investigation. Circulation 2002, 105:2253-2258.

13. Elsayed EF, Tighiouart H, Griffith J, Kurth T, et al: Cardiovascular disease and subsequent kidney disease. Arch Intern Med 2007, 167(11):1130-1136.

14. Fredman Bl: Chronic Kidney disease: cause and consequence of cardiovascular disease. Arch Intern Med 2007, 167(11):1113-1115.

15. Shamseddin MK, Parfrey PS: Sudden cardiac death in chronic kidney disease: epidemiology and prevention. Nat Rev Nephrol 2011, 7(3):145-154.

16. Naruse $Y$, Tada $H$, Sekiguchi $Y$, Machino T, Ozawa M, Yamasaki H, Igarashi M, Kuroki K, Itoh Y, Murakoshi N, Yamaguchi I, Aonuma K: Concomitant chronic kidney disease increases the recurrence of atrial fibrillation after 
catheter ablation of atrial fibrillation: a mid-term follow-up. Heart Rhythm 2011, 8(3):335-341

17. Couser WG, Riella MC: World Kidney Day 2011: Protect your kidneys, save your heart. Arch Med Sci 2011, 7:1-4.

18. Aronow WS, Banach M: Ten most important things to learn from the ACCF/AHA 2011 expert consensus document on hypertension in the elderly. Blood Press 2012, 21(1):3-5.

19. Yildirir A, Batur MK, Oto A: Hypertension and arrhythmia: blood pressure control and beyond. Europace 2002, 4:175-182.

20. Morin DP, Oikarinen L, Viitasalo M, Toivonen L, Nieminen MS, Kjeldsen SE, Dahlöf B, John M, Devereux RB, Okin PM: QRS duration predicts sudden cardiac death in hypertensive patients undergoing intensive medical therapy: the LIFE study. Eur Heart J 2009, 30(23):2908-2914.

21. Herzog CA: Cardiac arrest in dialysis patients: approaches to alter an abysmal outcome. Kidney Int 2003, 63(Suppl. 84):197-200.

22. Ganesh SK, Stack AG, Levin NW, Hulbert-Shearon T, Port FK: Association of elevated serum $\mathrm{PO} 4, \mathrm{Ca} \times \mathrm{PO} 4$ product, and parathyroid hormone with cardiac mortality risk in chronic hemodialysis patients. J. Am. Soc. Nephrol 2001, 12:2131-2138.

23. Herzog CA, Strief J, Collins AJ, Gilbertson DT: Cause-specific mortality of dialysis patients after coronary revascularization: why don't dialysis patients have better survival after coronary intervention? Nephrol Dial Transplant 2008, 23:2629-2633.

24. Pun PH, Smarz TR, Honeycutt EF, Shaw LK, Al-Khatib SM, Middleton JP: Chronic kidney disease is associated with increased risk of sudden cardiac death among patients with coronary artery disease. Kidney Int 2009, 76:652-658

25. Malyszko J, Zbroch E, Malyszko J, Mysliwiec M, laina A: The cardio-renalanaemia syndrome predicts survival in peritoneally dialyzed patients. Arch Med Sci 2010, 6:539-544

26. Karnik JA, Young BS, Lew NL, Herget M, Dubinsky C, Lazarus JM, Chertow GM: Cardiac arrest and sudden death in dialysis units. Kidney Int 2001, 60:350-357

27. Bleyer AJ, Hartman J, Brannon PC, Reeves-Daniel A, Satko SG, Russell G: Characteristics of sudden death in hemodialysis patients. Kidney Int 2006, 69:2268-2273.

28. Muller J, Kaufmann P, Luepker R, et al: Mechanisms precipitating acute cardiac arrest: review and recommendations of an NHLBI workshop. Circulation 1997, 96:3233-3239.

29. Wu VC, Huang JW, Wu MS, Chin CY, Chiang FT, Liu YB, Wu KD: The effect of iron stores on corrected QT dispersion in patients undergoing peritoneal dialysis. Am J Kidney Dis 2004, 44:720-728.

30. Koc Y, Unsal A, Kayabasi H, Oztekin E, Sakaci T, Ahbap E, Yilmaz M, Akgun AO: Impact of volume status on blood pressure and left ventricle structure in patients undergoing chronic hemodialysis. Ren Fail 2011, 33(4):377-381.

31. Stewart GA, Gansevoort RT, Mark PB, Rooney E, McDonagh TA, Dargie HJ, Stuart R, Rodger C, Jardine AG: Electrocardiographic abnormalities and uremic cardiomyopathy. Kidney Int 2005, 67:217-226.

32. Amann K, Kronenberg G, Gehlen F, Wessels S, Orth S, Münter K, Ehmke H, Mall G, Ritz E: Cardiac remodeling in experimental renal failure - an immunohistochemical study. Nephrol. DialTransplant 1998, 13:1958-1966.

33. Covic A, Diaconita M, Gusbeth-Tatomir P, Covic M, Botezan A, Ungureanu G, Goldsmith DJ: Hemodialysis increases QTc interval but not QTC dispersion in ESRD patients without manifest cardiac disease. Nephrol. Dial Transplant 2002, 17:2170-2177.

34. Beaubien ER, Pylypchuk GB, Akhtar J, Biem HJ: Value of corrected QT interval dispersion in identifying patients initiating dialysis at increased risk of total and cardiovascular mortality. Am J Kidney Dis 2002, 39:834-842.

35. Cicero AF, Ertek S: Preclinical and clinical evidence of nephro- and cardiovascular protective effects of glycosaminoglycans. Arch Med Sci 2010, 6(4):469-477

36. Rysz J, Banach M, Stolarek RA, Mikhailidis DP, Cialkowska-Rysz A, Pokoca L, Piechota M, Baj Z: Serum metalloproteinases MMP-2, MMP-9 and metalloproteinase tissue inhibitors TIMP-1 and TIMP-2 in patients on hemodialysis. Int Urol Nephrol 2011, 43(2):491-498.

37. Rysz J, Banach M, Cialkowska-Rysz A, Stolarek R, Barylski M, Drozdz J, Okonski P: Blood serum levels of IL-2, IL-6, IL-8, TNF-alpha and IL-1beta in patients on maintenance hemodialysis. Cell Mol Immunol 2006, 3(2):151-154.
38. Ravani $P$, et al: Asymmetrical dimethylarginine predicts progression to dialysis and death in patients with chronic kidney disease: a competing risks modeling approach. J Am Soc Nephrol 2005, 16:2449-2455.

39. Rysz J, Majewska E, Stolarek RA, Banach M, Ciałkowska-Rysz A, Baj Z: Increased levels of soluble TNF-alpha receptors and cellular adhesion molecules in patients undergoing bioincompatible hemodialysis. Am J Nephrol 2006, 26:437-444.

40. Shamseddin MK, Parfrey PS: Mechanisms of the cardiorenal syndromes. Nat Rev Nephrol 2009, 5:641-649.

41. Mallamaci F, Zoccali C, Tripepi G, Fermo I, Benedetto FA, Cataliotti A Bellanuova I, Malatino LS, Soldarini A, CREED Investigators: Hyperhomocysteinemia predicts cardiovascular outcomes in hemodialysis patients. Kidney Int 2002, 61:609-614.

42. Fadel Fl, Abdel Rahman AMO, Farouk M, et al: Plasma neutrophil gelatinase-associated lipocalin as an early biomarker for prediction of acute kidney injury after cardio-pulmonary bypass in pediatric cardiac surgery. Arch Med Sci 2012, 8:250-255.

43. Pamuccio V, Tripepi R, Tripepi G, Mallamaci F, Benedetto FA, Cataliotti A, Bellanuova I, Giacone G, Malatino LS, Zoccali C: Heart valve calcifications survival and cardiovascular risk in hemodialysis patients. Am J Kidney Dis 2004, 43:479-484.

44. Kitano Y, Kasuga H, Watanabe M, Takahashi H, Ibuki K, Kawade Y, Yasuda K, Iwashima S, Toriyama T, Matuo S, Kawahara H: Severe coronary stenosis is an important factor for induction and lengthy persistence of ventricular arrhythmias during and after hemodialysis. Am J Kidney Dis 2004, 44:328-336.

45. Parekh RS, Plantinga LC, Kao WH, Meoni LA, Jaar BG, Fink NE, Powe NR, Coresh J, Klag MJ: The association of sudden cardiac death with inflammation and other traditional risk factors. Kidney Int 2008, 74:1335-1342

46. Kowalczyk M, Banach M, Rysz J: Ferumoxytol: a new era of iron deficiency anemia treatment for patients with chronic kidney disease. J Nephrol 2011, 24(6):717-722.

47. Kanbay M, Solak Y, Covic A, Goldsmith D: Sudden cardiac death in patients with chronic kidney disease: prevention is the sine qua non. Kidney Blood Press Res 2011, 34(4):269-276.

48. Russo D, Corrao S, Miranda I, Ruocco C, Manzi S, Elefante R, Brancaccio D, Cozzolino M, Biondi ML, Andreucci VE: Progression of coronary artery calcification in predialysis patients. Am J Nephrol 2007, 27 (2):152-158

49. Alan C, Kocoglu H, Altıntas R, Alıcı B, Ersay AR: Protective effect of decorin on acute ischaemia-reperfusion injury in the rat kidney. Arch Med Sci 2011, 7:211-216.

50. Sharma R, Gaze DC, Pellerin D, Mehta RL, Gregson H, Streather CP, Collinson $\mathrm{PO}$, Brecker SJ: Ischemia-modified albumin predicts mortality in ESRD. Am J Kidney Dis 2006, 47:493-502.

51. Nishimura M, Tsukamoto K, Hasebe N, Tamaki N, Kikuchi K, Ono T: Prediction of cardiac death in hemodialysis patients by myocardial fatty acid imaging. J Am Coll Cardiol 2008, 51:139-145.

52. Johansson M, Gao SA, Friberg P, Annerstedt M, Bergström G, Carlström J, Ivarsson $T$, Jensen G, Ljungman S, Mathillas O, Nielsen FD, Strömbom U: Reduced baroreflex effectiveness index in hypertensive patients with chronic renal failure. Am J Hypertens 2005, 18:995-1000.

53. Johansson M, Gao SA, Friberg P, Annerstedt M, Carlström J, Ivarsson T, Jensen G, Ljungman S, Mathillas O, Nielsen FD, Strömbom U: Baroreflex effectiveness index and baroreflex sensitivity predict all-cause mortality and sudden death in hypertensive patients with chronic renal failure. J Hypertens 2007, 25:163-168.

54. Ritz E, Warnner C: The challege of sudden death in dialysis patients. Clin J Am Soc Nephrol 2008, 3:920-929.

55. Drechsler C, Meinitzer A, Pilz S, Krane V, Tomaschitz A, Ritz E, März W, Wanner C: Homoarginine, heart failure, and sudden cardiac death in haemodialysis patients. Eur J Heart Fail, 13(8):852-859.

56. Drechsler C, Krane V, Ritz E, März W, Wanner C: Glycemic control and cardiovascular events in diabetic hemodialysis patients. Circulation 2009 120(24):2421-2428.

57. Herzog CA, Asinger RW, Berger AK, Charytan DM, Díez J, Hart RG, Eckard KU, Kasiske BL, McCullough PA, Passman RS, DeLoach SS, Pun PH, Ritz E: Cardiovascular disease in chronic kidney disease. A clinical update from Kidney Disease: Improving Global Outcomes (KDIGO). Kidney Int 2011, 80(6):572-586. 
58. Banach M, Rysz J: Current problems in hypertension and nephrology. Expert Opin Pharmacother 2010, 11(16):2575-2578.

59. Bielecka-Dabrowa A, Aronow WS, Rysz J, Banach M: Current place of betablockers in the treatment of hypertension. Curr Vasc Pharmacol 2010, 8(6):733-741.

60. Chondal M, Goldenberg I, Moss AJ, McNitt S, Cheung AK: Risk factors for sudden cardiac death in patients with chronic renal insufficiency and left ventricular dysfunction. Am J Nephrol 2007, 27(1):7-14

61. Cice G, Ferrara L, D'Andrea A, D'Isa S, Di Benedetto A, Cittadini A, Russo PE, Golino P, Calabrò R: Carvedilol increases two-year survival in dialysis patients with dilated cardiomyopathy: a prospective, placebo-controlled trial. J Am Coll Cardiol 2003, 41:1438-1444.

62. Pun PH, Lehrich RW, Smith SR, Middleton JP: Predictors of survival after cardiac arrest in outpatient hemodialysis clinics. Clin J Am Soc Nephrol 2007, 2:491-500

63. Kozlowski D, Budrejko S, Lip GY, Mikhailidis DP, Rysz J, Raczak G, Banach M: Dronedarone: an overview. Ann Med 2012, 44:60-72

64. Fantuzzi S, Caico S, Amatruda O, Cervini P, Abu-Turky H, Baratelli L, Donati D, Gastaldi L: Hemodialysis-associated cardiac arrhythmias: a lower risk with bicarbonate? Nephron 1991, 58(2):196-200

65. Alagiakrishnan K, Banach M, Jones LG, Datta S, Ahmed A, Aronow WS: Update on diastolic heart failure or heart failure with preserved ejection fraction in the older adults. Ann Med 2012, doi:10.3109/ 07853890.2012.660493.

66. Gandhi K, Aronow WS, Desai H, Amin H, Lai HM, Frishman WH, Cohen M, Sorbera C: Incidence of appropriate cardioverter-defibrillator shocks and mortality in patients with implantable cardioverter-defibrillators with ischemic cardiomyopathy versus nonischemic cardiomyopathy at 33-month follow-up. Arch Med Sci 2010, 6:900-903.

67. Greenberg H, Case RB, Moss AJ, Brown MW, Carroll ER, Andrews ML, MADITII Investigators: Analysis of mortality events in the Multicenter Automatic Defibrillator Implantation Trial (MADIT-II). J Am Coll Cardiol 2004, 43(8):1459-1465.

68. Zipes DP, Camm AJ, Borggrefe M, American College of Cardiology/ American Heart Association Task Force; European Society of Cardiology Committee for Practice Guidelines; European Heart Rhythm Association; Heart Rhythm Society, et al: ACC/AHA/ESC 2006 Guidelines for Management of Patients With Ventricular Arrhythmias and the Prevention of Sudden Cardiac Death: a report of the American College of Cardiology/American Heart Association Task Force and the European Society of Cardiology Committee for Practice Guidelines (writing committee to develop Guidelines for Management of Patients With Ventricular Arrhythmias and the Prevention of Sudden Cardiac Death): developed in collaboration with the European Heart Rhythm Association and the Heart Rhythm Society. Circulation 2006, 114(10):e385-e484.

69. Sredniawa B, Mazurek M, Lenarczyk R, Kowalski O, Kowalczyk J, Kalarus Z: Early therapy following myocardial infarction: arguments for and against implantable cardioverter-defibrillators. Future Cardiol 2010, 6(3):315-323.

70. Solomon SD, Zelenkofske S, McMurray JJV, Finn PV, Velazquez E, Ertl G, Harsanyi A, Rouleau JL, Maggioni A, Kober L, White H, Van de Werf F, Pieper K, Califf RM, Pfeffer MA, for the Valsartan in Acute Myocardial Infarction Trial (VALIANT) Investigators: Sudden Death in Patients with Myocardial Infarction and Left Ventricular Dysfunction, Heart Failure, or Both. N Engl J Med 2005, 352:2581-2588.

71. Piotrowski G, Szymański P, Banach M, Piotrowska A, Gawor R, Rysz J, Gawor Z: Left atrial and left atrial appendage systolic function in patients with post-myocardial distal blocks. Arch Med Sci 2010, 6:892-899.

72. Dasgupta A, Montalvo J, Medendorp S, Lloyd-Jones DM, Ghossein C, Goldberger J, Passman R: Increased complication rates of cardiac rhythm management devices in ESRD patients. Am J Kidney Dis 2007, 49:656-663.

73. Hreybe H, Ezzeddine R, Bedi M, Barrington W, Bazaz R, Ganz LI, Jain S, Ngwu O, London B, Saba S: Renal insufficiency predicts the time to first appropriate defibrillator shock. Am Heart J 2006, 151:852-856.

74. Cuculich P, Sánchez JM, Kerzner R, Greenberg SL, Sengupta J, Chen J, Faddis MN, Gleva MJ, Smith TW, Lindsay BD: Poor prognosis for patients with chronic kidney disease despite ICD therapy for the primary prevention of sudden death. Pacing Clin Electrophysiol 2007, 30:207-213.

75. Korantzopoulos P, Liu T, Li L, Goudevenos JA, Li G: Implantable cardioverter defibrillator therapy in chronic kidney disease: a meta-analysis. Europace 2009, 11:1469-1475.
76. Herzog CA, Li S, Weinhandl ED, Strief JW, Collins AJ, Gilbertson DT: Survival of dialysis patients after cardiac arrest and the impact of implantable cardioverter defibrillators. Kidney Int 2005, 68(2):818-825.

77. Saxon LA, Bristow MR, Boehmer J, Krueger S, Kass DA, De Marco T, Carson P, DiCarlo L, Feldman AM, Galle E, Ecklund F: Predictors of sudden cardiac death and appropariate shock in the comparison of Medical Therapy. Circulation 2006, 114(25):2766-2772.

78. Amin MS, Fox AD, Kalahasty G, Shepard RK, Wood MA, Ellenbogen KA: Benefit of primary prevention implantable cardioverter-defibrillators in the setting of chronic kidney disease: a decision model analysis. J Cardiovasc Electrophysiol 2008, 19:1275-1280.

79. Meyer P, Desai RV, Mujib M, Feller MA, Adamopoulos C, Banach M, Lainscak M, Aban I, White M, Aronow WS, Deedwania P, Iskandrian AE, Ahmed A: Right ventricular ejection fraction $<20 \%$ is an independent predictor of mortality but not of hospitalization in older systolic heart failure patients. Int J Cardiol 2012, 155:120-125.

80. Sekhri V, Sanal S, DeLorenzo L, Aronow WS, Maquire GP: Cardiac sarcoidosis: a comprehensive review. Arch Med Sci 2011, 7:546-554

81. Graff B, Graff G, Koźluk E, Tokarczyk M, Piątkowska A, Budrejko S, Kozłowsk D, Dą̧browska-Kugacka A, Lewicka E, Świątecka G, Raczak G: Electrophysiological features in patients with sinus node dysfunction and vasovagal syncope. Arch Med Sci 2011, 7:963-970.

82. Nikolić G: Sudden bradycardia. Heart Lung 2011, 40(2):177-179.

83. Vardas PE, Auricchio A, Blanc JJ, Daubert JC, Drexler H, Ector H, Gasparini M, Linde C, Morgado FB, Oto A, Sutton R, Trusz-Gluza M, European Society of Cardiology; European Heart Rhythm Association: Guidelines for cardiac pacing and cardiac resynchronization therapy. The Task Force for Cardiac Pacing and Cardiac Resynchronization Therapy of the European Society of Cardiology. Developed in collaboration with the European Heart Rhythm Association. Europace 2007, 9(10):959-998.

84. Morgan JM: The MADIT II and COMPANION studies: will they affect uptake of device treatment? Heart 2004, 90:243-245.

85. Anand IS, Carson P, Galle E, Song R, Boehmer J, Ghali JK, Jaski B, Lindenfeld J, O'Connor C, Steinberg JS, Leigh J, Yong P, Kosorok MR, Feldman AM, DeMets D, Bristow MR: Cardiac resynchronization therapy reduces the risk of hospitalizations in patients with advanced heart failure: results from the Comparison of Medical Therapy, Pacing and Defibrillation in Heart Failure (COMPANION) trial. Circulation. 2009, 119(7):969-977.

86. Dickstein K, Vardas PE, Auricchio A, Daubert JC, Linde C, McMurray J, Ponikowski P, Priori SG, Sutton R, van Veldhuisen DJ, Committee for Practice Guidelines of the European Society of Cardiology: 2010 focused update of ESC Guidelines on device therapy in heart failure: an update of the 2008 ESC Guidelines for the diagnosis and treatment of acute and chronic heart failure and the 2007 ESC Guidelines for cardiac and resynchronization therapy. Developed with the special contribution of the Heart Failure Association and the European Heart Rhythm Association. Eur J Heart Fail 2010, 12:1143-1153.

87. Machnicki G, Lentine KL, Salvalaggio PR, Burroughs TE, Brennan DC, Schnitzler MA: Kidney transplant Medicare payments and length of stay: associations with comorbidities and organ quality. Arch Med Sci 2011, 7:278-286.

88. Malyszko J, Malyszko JS, Mikhailidis DP, Rysz J, Zorawski M, Banach M: Hypertension and kidney disease: is renalase a new player or an innocent bystander? J Hypertens 2012, 30:457-462.

89. Green D, Green HD, New DI, Kalra PA: The clinical significance of hyperkalaemia-associated repolarization abnormalities in end-stage renal disease. Nephrol Dial Transplant 2012, doi:10.1093/ndt/gfs129.

90. Barylski M, Małyszko J, Rysz J, Myśliwiec M, Banach M: Lipids, blood pressure, kidney - what was new in 2011? Arch Med Sci 2011, 7:1055-1066.

91. de Bie MK, Koopman MG, Gaasbeek A, Dekker FW, Maan AC, Swenne CA Scherptong RW, van Dessel PF, Wilde AA, Schalij MJ, Rabelink TJ, Jukema JW: Incremental prognostic value of an abnormal baseline spatial QRS-T angle in chronic dialysis patients. Europace 2012, doi:10.1093/europace/ eus306.

\section{doi:10.1186/1471-2369-13-162}

Cite this article as: Franczyk-Skóra et al:: Prevention of sudden cardiac death in patients with chronic kidney disease. BMC Nephrology 2012 13:162. 